\title{
Throughput Analysis on a Multi-state Manufacturing System by Considering Availability
}

\author{
Nabila Yuraisyah Salsabila ${ }^{1}$, Nurhadi Siswanto ${ }^{1 *}$, Erwin Widodo ${ }^{1}$, \\ Oryza Akbar Rochmadhan ${ }^{1}$
}

\begin{abstract}
The manufacturing technology becomes more complex as the customer's demand increases. Most of the manufacturing companies consist of multi-state manufacturing networks. Therefore, the reliability and availability parameters become important issues to satisfy customer demand. Unavailability can result in reducing throughput because of decreasing operational production time. To resolve this problem, the buffer inventory can minimize the occurrence of material starving and production blocking during the equipment downtime. This paper focus on experimenting with buffer inventory levels and the capacity of a multi-state manufacturing network to increase the production throughput on a company that has capacity 70,000 tons per year. However, due to the unavailability problem, the existing system capacity decreases to 62,175 tons per year. The simulation model is used to improve throughput by modeling the failure interruption and the buffer inventory logics during the production process. The experiment result shows that significant increases of the throughput to $64,744.8$ tons as a consequence of adding an initial stock in the buffer inventory.
\end{abstract}

Keywords: Throughput; buffer inventory; multi-state manufacturing system.

\section{Introduction}

Recently, Indonesia is in the stage of advancing and developing industries for the realization of national industries as the drivers of the national economy. This statement was written in the 2015-2035 National Industrial Development Master Plan (RIPIN 2015). Various types of industries have been built to support industrial development in Indonesia. There are ten industry groups prioritized based on RIPIN (Indonesian Ministry of Industry [1]).

The high demand for various products in Indonesia has resulted in the high value of imports of various product groups in Indonesia. In 2017, the industries with the highest import values were chemicals and goods from chemicals, followed by computers, electronic goods, and optics, while the food industry was in the third position. Indonesia can reduce the dependence on imports of these products by increasing the capability and ability of this industry to meet domestic needs by meeting the production targets of each industry. This can be done by developing and increasing the capacity of manufacturing system technology in the industry. The continuous manufacturing sys- tem is complex, so that production performance depends on the reliability and availability of these machines in producing products, especially for industries that have several stages of production (multi-state) (Chang, et al. [2]).

${ }^{1}$ Faculty of Industrial Technology, Department of Industria Engineering, Institut Teknologi Sepuluh Nopember, Л. Raya ITS, Surabaya 60111, Indonesia

Email: siswanto@ie.its.ac.id

* Corresponding author
Low reliability and availability of products can affect the production capacity. Production throughput will be reduced because of the low production operating time due to high-damage. Controlling the buffer inventory is one of the solutions to optimize throughput. The inventory buffer level can overcome the occurrence of material starving and production blocking. Starving and blocking can occur between two stages of production. Starving occurs when the second stage break down occurs in the first stage, so the material cannot flow to the next stage. While blocking occurs when the first stage stop producing occurs in the second stage so that the material that has been processed in the first stage cannot flow to the next stage.

Based on Macchi et al. [3], Figure 1 shows a twostage manufacturing system. There is a buffer inventory between the two stages of the manufacturing system, which accommodates work in process during the production process. Based on Macchi et $a l$. [3], Figure 2 shows the effect of damage in two stages of production on the level of buffer inventory. There are five types of patterns which are represented by pattern (a), (b), (c), (d), (e) and two states of buffer inventory level which are represented as state (1) and state (2). Pattern (a) shows the buffer inventory levels that increase and decrease regularly. This pattern occurs when the system operates, and no damage occurs. Regular increases and decreases in inventory levels occur when the production speeds at the two stages of production are the same. Patterns (c) and (e) indicate that the level of buffer inventory increases and decreases but irregular, this shows different production speeds at 
the two stages of production. Generally, this pattern occurs in stochastic systems. Pattern (b) shows the level of inventory buffer that continues to increase. This pattern indicates the occurrence of damage in the second stage so that the material cannot flow to the next stage. State (1) shows that the buffer inventory level has reached its maximum capacity. This condition will prevent the first stage produces a product because there is no more room left for the product. This event is called as blocking. Whereas the pattern $(d)$ the buffer inventory level continues to decline due to damage in the first stage. State (2) shows that there is no product in the buffer inventory, which caused the first stage of machine stops producing. This stage indicates a starving condition. Based on the changes of buffer inventory levels, decision-makers can carry out quantitative assessments to evaluate the isolation time provided by the buffer inventory levels. The buffer inventory level must be sufficient to meet repair interventions when the machine fails (Macchi et al. [3]).

A continuous industrial company is producing chemicals with a capacity of 70,000 tons in one year. In 2014-2017, the factory experienced several shutdowns, resulting in suboptimal production processes and resulting in $88.82 \%$ availability. This condition decreased production to $62,175.23$ tons on average in one year. At this plant, no losses occur, so that the availability of production only influences production capacity.

There are four stages of production: oxidation, sublimation, distillation, and bagging which work sequentially and are configured in series. Between the sublimation and distillation stages, three tanks function to accommodate WIP as well as a buffer inventory with a capacity of 100 tons each. There is also a buffer tank between the distillation and bagging stages with a capacity of 1000 tons and 600 tons. In this study, an experiment will be carried out on the buffer inventory to increase throughput.

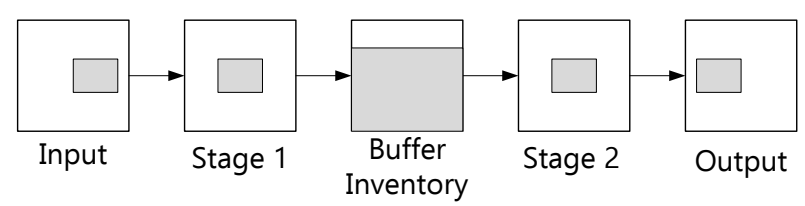

Figure 1. Two-stages manufacturing system (Macchi et al. [3])

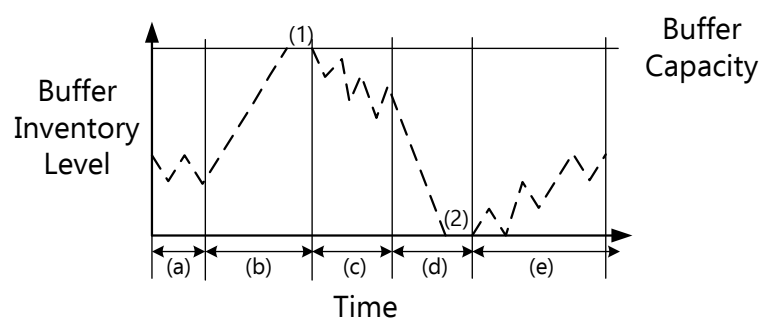

Figure 2. Buffer inventory level (Macchi et al. [3])
There are two types of approaches to perform this experiment, analytical and simulation. The analytical approach is made by representing the system with a mathematical model and evaluating the reliability index using a mathematical solution (Faulin [4]). In more complex cases, the analytical approach is too complex to be applied. Analytical approaches are generally used to evaluate mean values. However, the average value does not represent variability. In analyzing availability, a probability distribution is needed to represent MTTF and MTTR. So if analytical approaches are applied to systems that have random behavior, information about probability distributions cannot be obtained.

Several studies discuss various strategies to improve reliability, availability, and throughput. Reliability optimization was carried out by Fiondella et al. [5]. They built a model to reduce the negative impact of damage to production units on profitability. Generally, research related to reliability optimization assumes that each production unit is independent, but in this study, there is a comparison of the reliability of systems that are independent and correlated. Reliability analysis on the multi-state manufacturing network has been carried out in Macchi et al. [3]; Chang et al. [2]; Chang [6]; Chang, et al. [7]; Lai and Yeh [8]. Macchi et al. [3] researched this study by performing throughput analysis as support in developing maintenance strategy decisions. This research produces a model that is built based on the reliability block diagram (RBD). They also integrate RBD analysis and buffer inventory, taking into account the complexity of the system. Chang, et al. [7] conducted a system reliability study on a multi-state manufacturing network with multiple production lines (MSMN-MPL) by considering buffer inventory. This study uses a case study of a footwear product manufacturing system using limited or unlimited buffering capacity. Reliability analysis by modeling a multi-state manufacturing system was also conducted in Chang [6] study. This study aims to assess the level of customer satisfaction. Chang [6] defines system reliability as the probability that a multi-state manufacturing network (MMN) can provide sufficient capacity to meet customer needs. A simulation approach was carried out by Chang, et al. [7] to generate random capacity status to calculate the use of buffer inventory on a multi-state manufacturing network (MSMN) system. This study uses joint buffers to improve the reliability of the MSMN system. Lai and Yeh [8] applies the redundancy allocation problem (RAP) to multi-state systems. System availability cannot be evaluated on a multi-state system directly because the system configuration cannot be changed. So that in this study, they used a bridge system using the Particle Swarm Optimization (PSO) approach. 
Zahedi et al. [9] integrate a model of batch production and preventive maintenance scheduling on a single machine producing. They proposed a model to minimize the total cost consisting of inventory cost during the parts processing, setup cost, and cost of preventive maintenance. The decision variables are the frequency of preventive maintenance, the schedule, length of production runs, the number of batches, bath sizes, and the production schedule for each production run. The availability analysis has been carried out in Subiyanto [10]; Salsabila and Siswanto [11]. Subiyanto [10] applies the application of the Overall Equipment Effectiveness (OEE) method on 39 stateowned sugar factories. This study also identifies 19 worst factories inefficiency and gives some recommendation to restructure these factories. Salsabila and Siswanto [11] carried out an availability analysis by considering the spare parts inventory. This study simulates the whole production flow along with the spare part inventory level. They determine the optimal inventory parameters in $\mathrm{S}, \mathrm{s}$ policy by considering the machine failures in order to maximize the product availability and calendar days.

Random behavior patterns can occur in the time to failure and the time to repair. The behavior of a system follows the patterns of a probability distribution. The simulation approach is used to estimate the availability index by simulating the actual process and random behavior of a system and its components. This method simulates the behavior of components and systems chronologically. This method is also able to simulate the behavior of interdependence between components and variables in the system. By using a simulation approach, the results obtained can be either an average or a distribution of an index and other information that cannot be obtained only by an analytical approach. In this study, a simulation approach will be used to model the failure and production systems at the plant. The simulation model is carried out with a random concept; in this concept, the probability of an event is used. This random concept is based on data, so that from the simulation results, it can be concluded the description of various possible events and more representative of existing conditions.

Several contributions that will be provided in this paper are described as follows: (1) Referring to the previous studies, most of them are utilizing customer satisfaction, availability, reliability. To the best our knowledge, there are no simulation studies which considers the throughput as the performance measurement in the multi-state manufacturing company simultaneously. Most of the company do not consider production availability and reliability as the main performance measurement. They prefer to measure the production outputs because it will obviously contribute to the sales and demand fullfillment performances. (2) Furthermore, we will provide conceptual models as a representation of the real system. A flow diagram will be provided to represents the logical concept $f$ the real system. We will also provide all failure combinations in the production process. (3) A real-case study also will be used to evaluate our model through computational analysis.

\section{Methods}

\section{System and Problem Analysis}

The system to be modeled in this study consists of entities, activities, and resources. Entities are items that are processed through a system such as products, customers, and documents (Harrel et al. [12]). Entities in this system are raw materials that will be processed into finished products. Activities are work carried out in a system that is directly or indirectly involved in processing an entity. The activity which will be modeled on this system is the production process. There are four production units, namely oxidation, sublimation, distillation, and bagging which work sequentially and are configured in series. Resources act as a facility provider. If the resources are insufficient, it can result in activities in the system that are not optimal (Harrel et al. [12]). The resources to be modeled in this system are machines in each unit and tank as a buffer inventory. Table 1 and Table 2 show the buffer inventory capacity and the production rate, respectively.

Table 1. Buffer capacity

\begin{tabular}{lll}
\hline Tank & Location & $\begin{array}{l}\text { Total Capacity } \\
\text { (tons) }\end{array}$ \\
\hline \multirow{2}{*}{ Crude Tank } & Between Sublimation & $(3 \times 100$ tons $)=$ \\
and Distillation & 300 \\
Pure Tank & $\begin{array}{l}\text { Between Distillation } \\
\text { and Bagging }\end{array}$ & $(1000+600)=$ \\
\end{tabular}

Table 2. Production rate

\begin{tabular}{lc}
\hline Unit & Production Rate (ton/ hour) \\
\hline Oxidation & 11 \\
Sublimation & 10 \\
Distillation & 11 \\
Bagging & 10 \\
\hline
\end{tabular}

Table 3. System variables

\begin{tabular}{lll}
\hline Decision variables & Respond variable & State variable \\
\hline Buffer capacity & $\begin{array}{l}\text { Production } \\
\text { throughput }\end{array}$ & $\begin{array}{l}\text { Resource states } \\
\text { (busy/ idle/ failure) }\end{array}$ \\
$\begin{array}{l}\text { Initial buffer } \\
\text { inventory level }\end{array}$ & \\
\hline
\end{tabular}


There are three types of system variables in the simulation, namely decision variables, response variables, and status variables (Harrel et al. [12]). Decision variables can sometimes also be referred to as independent variables in an experiment. Changing the value of the decision variable can have an impact on the system as a whole. Decision variables consist of variables that can be controlled or variables that cannot be controlled (Harrel et al. [12]). In this study, we will utilize the buffer capacity and initial buffer stock as the decision variables. These decision variables will be considered as the scenario in this study. The response variable measures the performance of a system that impacts the change in decision variables (Harrel et al. [12]). In an experiment, the response variable is the dependent variable, which is the variable that depends on the policy of the independent variable. The status variable is the status of a variable at a certain point and time (Harrel et al. [12]). In general, the response variable is the response of the status variable measured from the beginning to the end of the system being simulated. Table 3 shows the simulation system variables that are determined based on the research objectives.

\section{Data Collection and Data Processing}

The data in the simulation consists of structural data, operational data, and numerical data. Table 4 shows the data that will be processed and used as input models in this study.

The production plant consists of four units, oxidation unit, sublimation unit, distillation unit, and bagging unit which configured in a series system. Each unit consists of many types of equipment which configured in series or parallel system. Oxidation unit consists of 14 critical machines, sublimation unit consists of 7 critical machines, distillation consists of 6 critical machines, and bagging unit consists of 4 critical machines. Each machine has a mean time to failure (MTTF) and mean time to repair (MTTR) historical data. We used the historical data from 2013-2017 to predict the failures based on certain distribution probability.

Table 4. Data requirements

\begin{tabular}{lll}
\hline Structural data & Operational data & \multicolumn{1}{c}{ Numerical data } \\
\hline Machines & Production flow & Production rate \\
Production & Machine & Time between failures \\
activity & configuration & \\
Buffer location & & Time to repair \\
& & $\begin{array}{l}\text { Production targets } \\
\text { Production schedules }\end{array}$ \\
& & Buffer inventory \\
& & capacity \\
\hline
\end{tabular}

Random properties in the simulation model are represented in the distribution of random numbers. This distribution is obtained from the result of fitting with the smallest error. In this model, random data is the time between failures (MTTF) and the time to repair (MTTR). MTTF can be represented by Weibull distribution, while MTTR can be represented by a normal distribution (Siswanto et al. [13]).

\section{Scenario Development}

There are two buffer inventory units arranged between production units. This buffer inventory can be used to avoid starving and blocking, as described in Figure 2. The scenario design to be developed is as follows:

Scenario 1: Increase buffer inventory capacity. The buffer capacity is used as the decision variable because it can potentially decrease the blocking and starving occurrence. Suppose a failure occurs in the second stage of the production process. The higher buffer capacity can accommodate the higher work in process resulted from the first stage. Therefore, the blocking occurance will be minimized.

Scenario 2: Determine the initial stock in the buffer inventory. The initial buffer inventory level can minimize the starving occurance while failure occurs. Suppose failure occurs in the first stage of the manufacturing process, if there is no stock in the buffer inventory afterwards, the second stage of the manufacturing process can not produce because there is no feed and then the starving occurs. The initial buffer inventory can be a practical alternative because it can feed the second stage of the manufacturing process while the first stage of the manufacturing process fails.

\section{Model Development}

In simulation studies, first, the concept modeling is done, and then it will be developed into the simulation modeling. Conceptual models will be constructed so that it can be easier for modelers in preparing simulation models. In this study, the concept model is described in the form of a flow diagram.

\section{Verification and Validation}

Model verification is the process of determining whether the simulation model already represents a conceptual model (Harrel et al. [12]). The purpose of verifying the model is to ensure that the model has been built correctly so that errors do not occur. A syntax error is a mistake in writing code, while the semantic error is a logic model error (Harrel et al. [12]). As for several ways, you can do to verify the model: (1) Review the model code, (2) Test the output 
(3) Look at animations to ensure the logic of the model (4) Using trace and debug facilities that exist in the software.

Validation is determining whether the model is an accurate representation of the actual system (Harrel et al. [12]). Model validation aims to assess whether the model is following empirical data or models on the actual system. If the model is following the actual system, then performance measures will also be appropriate if applied to the actual system. Some of the techniques for model validation are as follows: (1) See animations, (2) Comparing with the actual system, (3) Compare with other models, (4) Perform degeneration tests and extreme conditions,(5) Ask for help from those who have more knowledge to test the validity of the model,(6) Test against historical data, (7) Conduct sensitivity analysis

\section{Model Development Failure Combinations}

To model, the relationship between damage and the production process, an analysis of the combination of damage to the production process is carried out. The following lists are combinations of damage to the production process.

$w \mathbf{2}<t \mathbf{1}$ and $w 1<t 1$

In this combination, damage does not occur in the production period, so the production time does not increase due to damage.

Based on Figure 3 it can be seen that the occurrence of damage will not affect the length of the production process. So, the processing time (T) is as follows:

$T=t_{2}-t_{1}$

$\mathrm{t}_{1}>\mathrm{w}_{1}$ and $\mathrm{t}_{2}<\mathrm{w}_{2}$

In this combination, damage occurs first and still occurs until the production process is completed.

If this combination of damage occurs in the production process, the time of the production process will increase according to the time of damage. So, the processing time $(\mathrm{T})$ is as follows:

$T=\left(t_{2}-t_{1}\right)+\left(w_{2}-w_{1}\right)$

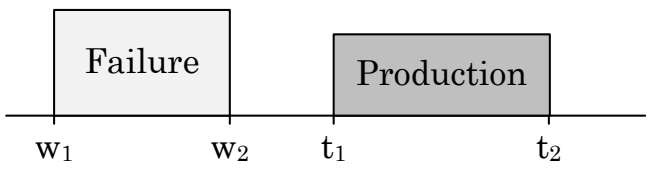

Figure 3. Failure combination 1

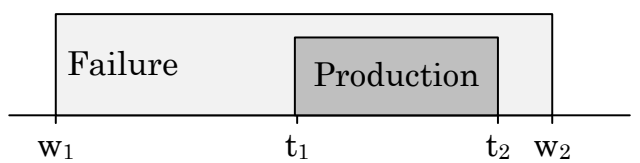

Figure 4. Failure combination 2

\section{$t_{1}>w_{1}$ and $t_{2}>w_{2}$}

In this combination, damage occurs before the production process begins, but will end before the production process ends.

This combination of damage results in increased production processing time, so the processing time (T) is as follows:

$T=\left(t_{1}-w_{1}\right)+\left(w_{2}-t_{1}\right)+\left(t_{2}-w_{2}\right)$

$\mathrm{t}_{1}<\mathrm{w}_{1}$ and $\mathrm{t}_{2}<\mathrm{w}_{2}$

In this combination, the damage starts in the middle of the production process, so the production process will stop in the middle after the repair process is finished.

The occurrence of this combination of damage causes the production process time to stop in the middle so that it increases. The following is the formula for calculating production time $(\mathrm{T})$ :

$T=\left(w_{1}-t_{1}\right)+\left(w_{2}-w_{1}\right)+\left(t_{2}-w_{1}\right)$

$t_{1}<w_{1}$ and $t_{2}>w_{2}$

In this combination, the damage starts after the production process begins and ends before the production process ends, so the production process will stop in the middle and will continue after repairs are made.

This combination of damage causes the production process to increase according to the time of damage so that the processing time (T) can be calculated with the following formula:

$T=\left(t_{2}-t_{1}\right)+\left(w_{2}-w_{1}\right)$

where:

$T=$ total production time

$t_{1}=$ production start time

$t_{2}=$ production complete time

$w_{1}=$ repair start time

$w_{2}=$ repair complete time

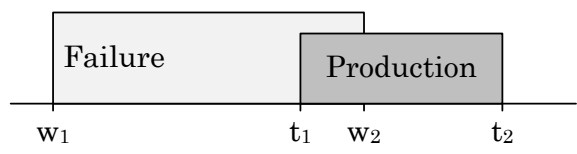

Figure 5. Failure combination 3

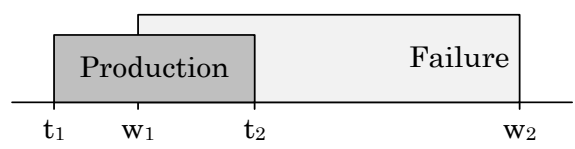

Figure 6. Failure combination 4

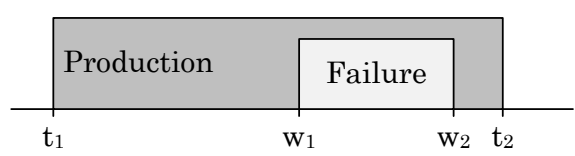

Figure 7. Failure combination 5 


\section{Buffer Inventory Model}

Based on the existing conditions, the buffer inventory is between the sublimation and distillation process with a capacity of $300 \mathrm{MT}$, and between the distillation and bagging process with a capacity of 1600 MT.

The amount of WIP in the oxidation unit needs to have value less than 11 to change the continuous into discrete values. The case study is a continuous production facility, while the simulation approach we used in this experiment is the discrete event simulation. To overcome this, we approach the materials as discrete values by utilizing the production rate of 11 tons/hour as the production capacity. We model all the production time in an hour and limit the production capacity. Since the production capacity of the oxidation unit is 11 tons as shown in Table 2, the material can be processed in the oxidation unit if the work in process in the oxidation unit is not greater than 11 tons. Otherwise, the materials will be kept in the material storage. The same logic is also applied in all units, except if there is a buffer inventory, the materials will be stored as a buffer. Figure 8 displays the conceptual modeling of the buffer inventory subsystem.

The flow starts from the arrival of the material and the oxidation process. Materials arrival based on the number of demands and production schedules. The next step is evaluating whether the oxidation unit capacity is sufficient and does not fail. If so, then the oxidation process can be carried out. This evaluation process is not an oxidation blocking process because this evaluation is carried out in the raw material subsystem. After the oxidation process has been carried out, an evaluation is made whether the sublimation unit has sufficient capacity. If sufficient, then the next process is the sublimation process. If not, then the material must wait until the capacity of the sublimation unit is sufficient and does not fail. At this stage, there is no inventory buffer because the material is still in the form of gas.

Table 5. Simulation result of the existing condition

\begin{tabular}{|c|c|}
\hline Replication & Throughput \\
\hline 1 & 65,318 \\
\hline 2 & 61,898 \\
\hline 3 & 64,945 \\
\hline 4 & 61,711 \\
\hline 5 & 62,333 \\
\hline 6 & 64,446 \\
\hline 7 & 63,579 \\
\hline 8 & 62,358 \\
\hline 9 & 61,217 \\
\hline 10 & 60,893 \\
\hline Average & $62,869.80$ \\
\hline hw & $1,137.62$ \\
\hline
\end{tabular}

After the sublimation unit capacity is sufficient and does not fail, the process continues to the distillation process. In this process, there is a buffer inventory with a capacity of $300 \mathrm{MT}$, so it is necessary to evaluate whether the capacity of the buffer inventory is sufficient. If enough, the material can enter the buffer inventory and release the sublimation unit resource. If not, then the material will experience blocking, so that the material after that cannot be processed in the sublimation unit. The material will be released in the buffer inventory and will be processed in the distillation unit if the capacity of the distillation unit is sufficient and not damaged.

After the distillation process is carried out, the next step is to evaluate whether the capacity in the buffer inventory is sufficient, if enough, the material will be released from the distillation unit and go to the distillation buffer inventory. If the capacity of the bagging unit is sufficient and has not been damaged, then the material can be processed in the bagging unit.

\section{Verification and Validation}

In this study, verification is done by using the check model and animation features of the software. We create animations that describe the production process based on flow diagrams in Figure 8. Model logic is compared with logic in flow diagrams. If the logic is appropriate, then the simulation model can be built. In addition to animation, we also display graphs and variables in the production subsystem and buffer inventory.

The variables displayed in the production subsystem are used to test the logic of production time and improvement in each unit. If a failure occurs in the range of the production process, then the material time in the system is added to the repair process time. If not, then the material will be processed immediately to the next stage.

The variables displayed in the buffer inventory submodel are used to ensure that the number of queues in blocking does not exceed production capacity, and the number of queues in buffer inventory does not exceed buffer inventory capacity. Table 5 shows the production throughput based on simulation results.

The simulation is done in 10 replications, so it needs to be proven whether the number of replications is enough. Based on the simulation results, the value of halfwidth (hw) throughput is 1,137.62. This value will then be compared with the maximum halfwidth limit allowed based on our degree of error. We will refer the calculation of hw value based on (Siswanto et al. [13]), which is formulated as follows:

$h w_{e}=e$ 
The replication numbers are satisfied if the following requirements is fulfilled (Siswanto et al. [13]):

$h w_{s}<h w_{e}$

Based on production capacity, the factory can produce 70,000 tons per year, but the existing conditions indicate that the availability of production is $88.82 \%$. Since there are no losses through the production process, the maximum capacity of the throughput becomes 62.175.23 tons in one year. Equation 8 and Equation 9 show the calculation of the expected $h w$.

$h w_{s}=5 \%(62,175.23)$

$h w_{s}=3,108.76$

Based on the results of the calculation of equation (8) and (9), the expected hw value is greater than the simulation hw. Therefore, it can be concluded that the number of 10 replications is enough to represent the simulation output. Equation 10, Equation 11, and Equation 12 show the calculation of the number of replications that are needed

$n^{\prime}=\left[\frac{z_{\alpha / 2} s}{h w}\right]^{2}$

$n^{\prime}=\left[\frac{1.96(1,590.39)}{1,137.62}\right]^{2}$

$n^{\prime}=7.508$

where:

$h w_{e}$ : expected half width

$h w_{s}$ : simulation half width

$e \quad$ : expected degree of error (\%)

Based on the calculation results, the number of replications needed is 8 . This value is also still less than the number of replications that have been done, so it can be concluded that ten replications are enough.

Validation is done by testing population simulation results and existing data with the following hypotheses:

$h_{0}: \mu_{\text {simulation }}=\mu_{\text {existing }}$

$h_{A}: \mu_{\text {simulation }} \neq \mu_{\text {existing }}$

Since we use $\alpha=0.05$ degree of error and the degree of freedom $n-1=10-1=9$, the $t$-critical is \pm 2.2622 . The one-sample t-statistics shows that the t-value of the statistics result is 1.38 , which is within the interval [$2.2622 ; 2.2622]$. Therefore, we can conclude that $\mathrm{h}_{0}$ is accepted or there is no significant difference in the two populations.

\section{Analysis}

\section{Existing Conditions}

The factory has two buffer inventories. The buffer inventory capacity in the sublimation unit is three tanks of 100-ton capacity, and the distillation unit is 1600 tons. The factory production capacity is 70,000 tons per year, while the company can only produce as much as $62,175.23$ tons in one year due to production disruptions. This production disruption is caused by a disruption in the supply of raw materials and disruption on the production floor. To increase production throughput, experiments can be carried out on buffer inventory. Table 6 shows the throughput parameters of the simulation results with 10 replications. The average throughput generated is $62,869.80$.

Table 6 shows the average stock of WIP material and blocked material in the buffer inventory. The average WIP stock in the sublimation buffer inventory is 4.9 tons, while the distillation buffer inventory is 0.68 tons. In the third replication, the sublimation buffer stock reaches the maximum capacity, which is 300 tons. To analyze the occurrence of blocking in the buffer inventory, an average amount of material that has been blocked during production is recorded. Blocking is the cessation of the production process because there are units that are experiencing damage. The unit will then hamper the previous process. Therefore, a buffer inventory is needed to collect the product that will be processed in the unit that is experiencing damage so that the production process will continue to run while waiting for the unit repair process.

Although the chance of blocking is quite low, in the second replication there is blocking in the sublimation unit of 11 tons. So, it can be concluded that the amount of buffer inventory stock exceeds the buffer capacity. This is consistent with replication 3 in Table 6, which shows that the buffer stock reaches the maximum buffer inventory capacity. Therefore, there are two scenario experiments as follows:

Scenario 1: Increase the buffer inventory capacity.

Scenario 2: Determining the initial stock in the buffer inventory.

\section{Scenario 1: increase buffer inventory capacity}

Blocking occurs when the amount of stock in the buffer inventory exceeds capacity. So that one solution to overcome the blocking is to increase the buffer inventory capacity. Since the existing condition of the sublimation capacity in the sublimation, unit is 3 tanks, and each tank's capacity is $100 \mathrm{MT}$. We try to add one more tank to test whether is there any significant difference by adding one tank or not. So that the total buffer inventory capacity will be 400 tons. Table 7 shows the throughput of experimental results and average buffers under the scenario of increasing buffer inventory capacity and the average amount of production throughput is $62,869.8$. 
Table 6. Average blocking existing condition

\begin{tabular}{lllllllll}
\hline \multirow{2}{*}{ Replication } & \multicolumn{2}{l}{ Sublimation Buffer } & \multicolumn{2}{l}{ Distillation Buffer } & \multicolumn{2}{c}{ Sublimation Blocking } & \multicolumn{2}{c}{ Distillation Blocking } \\
\cline { 2 - 8 } & Average & Max. & Average & Max. & Average & Max. & Average & Max. \\
\hline 1 & 0.1 & 1 & 1.5 & 79 & 0 & 0 & 0 & 0 \\
2 & 0.02 & 1 & 0.36 & 39 & 0 & 0 & 0 & 0 \\
3 & 36.08 & 300 & 0.63 & 59 & 0.14 & 11 & 0 & 0 \\
4 & 0.19 & 1 & 0.2 & 29 & 0 & 0 & 0 & 0 \\
5 & 2.99 & 121 & 0.77 & 49 & 0 & 0 & 0 & 0 \\
6 & 1.14 & 80 & 0.62 & 75 & 0 & 0 & 0 & 0 \\
7 & 7.18 & 220 & 1.11 & 59 & 0 & 0 & 0 & 0 \\
8 & 0.08 & 1 & 0.78 & 45 & 0 & 0 & 0 & 0 \\
9 & 0.08 & 1 & 0.35 & 39 & 0 & 0 & 0 & 0 \\
10 & 1.67 & 121 & 0.51 & 39 & 0 & 0 & 0 & 0 \\
\hline Average & 4.95 & 84.7 & 0.68 & 51.2 & 0.014 & 1.1 & 0 & 0 \\
\hline
\end{tabular}

Table 7. Average buffer inventory level and throughput of scenario 1

\begin{tabular}{llllll}
\hline \multirow{2}{*}{ Replication } & \multirow{2}{*}{ Throughput } & \multicolumn{2}{l}{ Sublimation Buffer } & \multicolumn{2}{l}{ Distillation Buffer } \\
\cline { 3 - 6 } & & Average & Maximum & Average & Maximum \\
\hline 1 & 65,318 & 0.1 & 1 & 1.5 & 79 \\
2 & 61,898 & 0.02 & 1 & 0.38 & 39 \\
3 & 64,945 & 40.2 & 311 & 0.63 & 59 \\
4 & 61,711 & 0.19 & 1 & 0.2 & 29 \\
5 & 62,333 & 2.99 & 121 & 0.77 & 49 \\
6 & 64,446 & 1.14 & 80 & 0.62 & 59 \\
7 & 63,579 & 7.18 & 220 & 1.11 & 45 \\
8 & 62,358 & 0.08 & 1 & 0.77 & 39 \\
9 & 61,217 & 0.08 & 1 & 0.35 & 39 \\
\hline Average & 60,893 & 1.67 & 121 & 0.51 & 51.2 \\
\hline
\end{tabular}

Table 8. Average buffer inventory level and throughput of scenario 2

\begin{tabular}{|c|c|c|c|c|c|c|c|}
\hline \multirow{2}{*}{ Replication } & \multirow{2}{*}{ Throughput } & \multicolumn{2}{|c|}{ Sublimation Buffer } & \multicolumn{2}{|c|}{ Distillation Buffer } & \multicolumn{2}{|c|}{ Sublimation Blocking } \\
\hline & & Average & Maximum & Average & Maximum & Average & Maximum \\
\hline 1 & 67,218 & 10.75 & 290 & 140.82 & $1,589.00$ & 0 & 0 \\
\hline 2 & 63,798 & 1.41 & 290 & 66.04 & $1,589.00$ & 0 & 0 \\
\hline 3 & 66,845 & 45.13 & 300 & 148.17 & $1,589.00$ & 0.14 & 11 \\
\hline 4 & 63,611 & 1.22 & 290 & 91.41 & $1,589.00$ & 0 & 0 \\
\hline 5 & 64,224 & 7.31 & 300 & 98.68 & $1,589.00$ & 0.01 & 10 \\
\hline 6 & 66,346 & 10.22 & 300 & 93.32 & $1,589.00$ & 0 & 0 \\
\hline 7 & 65,267 & 11.58 & 300 & 84.08 & $1,589.00$ & 0.06 & 11 \\
\hline 8 & 64,258 & 1.28 & 290 & 93.27 & $1,589.00$ & 0 & 0 \\
\hline 9 & 63,117 & 3.82 & 290 & 69.19 & $1,589.00$ & 0 & 0 \\
\hline 10 & 62,764 & 61.16 & 300 & 66.6 & $1,589.00$ & 0.01 & 11 \\
\hline Average & $64,744.80$ & 15.39 & 295 & 95.16 & $1,589.00$ & 0.02 & 4.3 \\
\hline
\end{tabular}

Based on experimental results, it can be concluded that increasing capacity does not affect throughput, but only affects blocking that occurs in the production process. Furthermore, there are no experiments that reach the maximum buffer inventory capacity, so it can be concluded that there was no blocking during the production process.

\section{Scenario 2: determine the initial buffer inven- tory level}

In this scenario, the initial stock inventory of the distillation buffer and sublimation capacity is deter- mined. This experiment was carried out because the probability of blocking is very small, which indicates that the buffer inventory capacity is very large. Since there is a sufficient buffer capacity, we try to utilize these capacity by fulfilling the initial buffer stock by $100 \%$ of capacity. Table 8 shows the throughput of experimental results and average buffer by adding initial stock to the buffer inventory.

Based on Table 8, it can be seen that the average throughput generated from the experiments is $64,744.8$ tons. Throughput increased by 1,875 tons compared to existing conditions. Blocking occurs in 
the sublimation buffer inventory while distillation buffer inventory does not occur. Table 8 shows blocking in the sublimation buffer inventory. Blocking occurs in replication $3,5,7$, and 10 . However, the amount of material undergoing blocking is quite small, so it can be concluded that this scenario is more feasible to be applied to the production process compared to scenario 1 . The maximum value of the distillation buffer is always 1,589 tons because the capacity of the distillation buffer is always full during the simulation (1,600 tons) and it is constantly decreased for the bagging process (11 tons) in the next step. Therefore we can conclude that the distillation buffer inventory is not necessary full from the beginning of the production process.

\section{Discussions}

The existence of initial stock in the buffer inventory can minimize calendar day, but there is also a risk of blocking the production unit. However, when viewed from the results of the existing condition simulation in Table 8, the probability of blocking is very low; this is because the buffer inventory capacity is sufficient for production needs.

We can use statistical analysis to test whether is there any significant effects of these scenarios to the production throughput. Next, we will utilize Minitab to conduct the ANOVA test with the hypothesis as follows:

$h_{0}: \mu_{\text {existing }}=\mu_{\text {scenario } 1}=\mu_{\text {scenario } 2}$

$h_{A}$ : at least one mean is different

Under the degree of error $\alpha=0.05$, degree of freedom $1=2$, and the degree of freedom $2=27$, the decision scenario is to reject ho if the F-value is larger than Fcritical 3.35.

The first part of the Minitab result shows the oneway ANOVA result. Based on this result, the Fvalue is larger than F-critical 3.35. Therefore we can conclude that at least one mean different. To determine which scenario gives a significant effect, we can see the Tukey Pairwise Comparisons. Based on this result, the significant effect is resulted in Scenario 2.

\section{Conclusion}

This research has produced a model to represent manufacturing systems in chemical company case studies. In this study, the model verification was also performed by displaying a buffer inventory level chart and equipment status.
Experiments on buffer inventory are carried out with two scenarios, namely by increasing the buffer inventory capacity and determining the initial stock of buffer inventory. Based on experimental results, increasing buffer inventory capacity does not affect production throughput, because in this case, the probability of material starving, and production blocking is very low. Thus, buffer inventory can be utilized by providing initial stock in buffer inventory. An additional production cost may be incurred because this scenario requires an additional production process at the beginning of the production schedule. However, this scenario gives more significant effects than expanding the buffer inventory capacity, which requires an investment cost.

Based on the simulation results, the average factory production capacity is $62,869.8$ tons per year. After the initial stock of buffer inventory was added, the factory production capacity increased to $64,744.80$ tons per year. Based on the results of the hypothesis test, it can be concluded that the production throughput increased significantly compared to the existing conditions.

\section{Acknowledgement}

The author would like to acknowledge this research funding from the Ministry of Research Technology and Higher Education, the Republic of Indonesia through the Postgraduate Thesis Research Grant Scheme No. 780 / PKS / ITS / 2019.

\section{References}

1. Indonesian Ministry of Industry. 2017 Indonesian Import-Export Processing Industry Report. Indonesian Ministry of Industry, 2017, https://kemenperin.go.id/download/19434/Lapora n-Ekspor-Impor-Hasil-Pengolahan-2018-Juni.

2. Chang, P.C., Lin, Y.K., and Chen, J.C. System Reliability for a Multi-State Manufacturing Network with Joint Buffer Stations, Journal of Manufacturing Systems, 42, Jan. 2017, pp. 17078. DOI.org (Crossref), doi:10.1016/j.jmsy.2016. 12.009.

3. Macchi, M., Kristjanpoller, F. Introducing Buffer Inventories in the RBD Analysis of Process Production Systems. Reliability Engineering \& System Safety, 104, Aug. 2012, pp. 84-95. DOI.org (Crossref), doi:10.1016/j.ress.2012.03.015.

4. Faulin, J., editor. Simulation Methods for Reliability and Availability of Complex Systems. Springer, 2010.

5. Fiondella, L., Lin, Y., Pham, H., Li C. A Confidence-Based Approach to Reliability Design Considering Correlated Failures. Reliability Engineering \& System Safety, 165, Sept. 2017, 
pp. 102-14. DOI.org (Crossref), doi:10.1016/j.ress. 2017.03.025.

6. Chang, P.C. A Simulation Analysis of the Impact of Finite Buffer Storage on Manufacturing System Reliability. Simulation Modelling Practice and Theory, 70, Jan. 2017, pp. 149-58. DOI.org (Crossref), doi:10.1016/j.simpat.2016.10. 006.

7. Chang, P.C., Lin, Y.K., and Chiang, Y.M. System Reliability Estimation and Sensitivity Analysis for Multi-State Manufacturing Network with Joint Buffers - A Simulation Approach. Reliability Engineering \& System Safety, vol. 188, Aug. 2019, pp. 103-09. DOI.org (Crossref), doi:10.1016/ j.ress.2019.03.024.

8. Lai, C.M., and Yeh, W.C. Two-Stage Simplified Swarm Optimization for the Redundancy Allocation Problem in a Multi-State Bridge System. Reliability Engineering \& System Safety, vol. 156, Dec. 2016, pp. 148-58. DOI.org (Crossref), doi:10.1016/j.ress.2016.07.025.
9. Zahedi, Z., Samadhi, TMA., Suprayogi, S., Halim, A.H. Model Integrasi Penjadwalan Produksi Batch dan Penjadwalan Perawatan dengan Kendala Due Date. Jurnal Teknik Industri, 16(2), Dec. 2014, pp. 73-82. DOI.org (Crossref), doi:10.9744/jti.16.2.73-82.

10. Subiyanto, S. Analisis Efektifitas Mesin/Alat Pabrik Gula Menggunakan Metode Overall Equipments Effectiveness. Jurnal Teknik Industri, 16(1), May 2014, pp. 43-52. DOI.org (Crossref), doi:10.9744/jti.16.1.43-52.

11. Salsabila, N. Y., and Siswanto, N. A Simulation Study of Availability Analysis on a Chemical Process Industry Considering Spare Part Inventory. IOP Conference Series: Materials Science and Engineering (Presented Paper), 2019.

12. Harrel, C., Gosh, B. K., Bowden, R. O. Simulation Using Promodel. Mc. Graw Hill, 2004.

13. Siswanto, N., Latiffianti, E., Wiranto, S. E. Simulasi Sistem Diskrit (Implementasi Dengan Software Arena). ITS Teknosains, 2018. 